\title{
Electrochemical and AFM Study of Inhibitory Properties of Thin Film Formed by Tartrazine Food Additive on 304L Stainless Steel in Saline Solution
}

\author{
Adriana Samide ${ }^{1, *}$, Gabriela Eugenia Iacobescu ${ }^{2, *}$, Bogdan Tutunaru $^{1}$, Cristian Tigae $^{1}$ \\ ${ }^{1}$ University of Craiova, Faculty of Sciences, Department of Chemistry, Calea Bucuresti 107i, Craiova, \\ Dolj, Romania \\ ${ }^{2}$ University of Craiova, Faculty of Sciences, Department of Physics, A.I. Cuza, no.13, Craiova, Dolj, \\ Romania \\ *E-mail: samide_adriana@yahoo.com; gabrielaiacobescu@yahoo.com
}

doi: $10.20964 / 2017.03 .62$

Received: 18 December 2016 / Accepted: 23 January 2017 / Published: 12 February 2017

\begin{abstract}
Tartrazine, IUPAC name: Trisodium (4E)-5-oxo-1-(4-sulfonatophenyl)-4-[(4-sulfonatophenyl) hydrazono]-3-pyrazolecarboxylate, effect on the corrosion rate of 304L stainless steel used as canned food packaging has been studied by estimating the inhibitory properties of the organic film formed on the alloy surface during the electrochemical measurements performed in saline solution containing 0.9 $\% \mathrm{NaCl}$, without and with tartrazine inhibitor. AFM technique revealed the main surface changes of steel corroded in saline blank solution as well as in saline solution containing tartrazine food additive compared to standard stainless steel sample. A level of $92.8 \%$ inhibition efficiency (IE) was reached for tartrazine inhibitor on 304L stainless steel corrosion in saline environment that involves a high degree of surface coverage at studied concentrations. Temkin adsorption model fitted well the experimental data, obtaining for the standard adsorption free energy $\left(\Delta G_{\text {ads }}^{\mathrm{o}}\right)$ the value of $-37.62 \mathrm{~kJ}$ $\mathrm{mol}^{-1}$. Consequently gradual transition from physical adsorption to chemisorption takes place, and finally the moderate chemical adsorption prevails. The AFM parameters like: the values of the average roughness $\left(R_{\mathrm{a}}\right)$, RMS roughness $\left(R_{\mathrm{q}}\right)$ and maximum peak-to-valley height $\left(R_{\mathrm{p}-\mathrm{v}}\right)$ showed that a smoother surface of $304 \mathrm{~L}$ stainless steel was obtained in the tartrazine presence compared to that was observed in its absence, suggesting that the inhibitor film was formed on the alloy surface.
\end{abstract}

Keywords: Tartrazine; Inhibitory Coating; 304L Stainless Steel; Electrochemical Measurements; AFM.

\section{FULL TEXT}


(C) 2017 The Authors. Published by ESG (www.electrochemsci.org). This article is an open access article distributed under the terms and conditions of the Creative Commons Attribution license (http://creativecommons.org/licenses/by/4.0/). 